ORIGINAL ARTICLE

\title{
Volume guarantee ventilation, interrupted expiration, and expiratory braking
}

N McCallion, R Lau, P A Dargaville, C J Morley

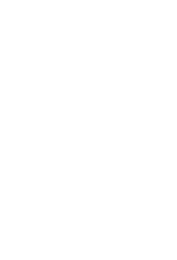

Arch Dis Child 2005;90:865-870. doi: 10.1136/adc.2004.061390

See end of article for authors' affiliations

Correspondence to:

Prof. C Morley, Neonatal Services, Royal Women's Hospital, Carlton, VIC 3070, Australia; colin.morley@rwh.org.au

Accepted 1 February 2005 Published Online First 10 May 2005

\begin{abstract}
Background: In volume guarantee ventilation with the Dräger Babylog 8000 ventilator, inspiratory and expiratory flows are monitored and the expiratory tidal volume calculated following each inflation. The pressure for the next inflation is modified to ensure the expired tidal volume is close to the set value.

Aim: To investigate interrupted expiration observed during volume guarantee ventilation of spontaneously breathing, ventilated infants.

Methods: Spontaneously breathing infants, ventilated with volume guarantee, had recordings of gas flow, ventilator pressures, tidal volume waveforms, oximetry, heart rate, and transcutaneous oxygen and carbon dioxide during 10 minute recordings.

Results: A total of 6540 inflations were analysed from 10 infants; $62 \%$ were triggered. Two different patterns were found: (1) Normal volume guarantee pattern with $97 \%$ of triggered and $91 \%$ untriggered inflations. It had a normal expiratory curve and a mean expired tidal volume within $3 \%$ of the set volume, but a large variation due to the babies' breathing. (2) A pattern of interrupted expiratory flow after $\sim 3 \%$ of inflations due to a small inspiration $(\sim 1.3 \mathrm{ml} / \mathrm{kg})$ during expiration. This led the ventilator to calculate an inappropriate total expired tidal volume for that inflation and an increase in the pressure for the next inflation.

Conclusions: After about $3 \%$ of inflations, with volume guarantee ventilation, interruption of the expiration causes an increased pressure for the next inflation of $\sim 4.9 \mathrm{~cm} \mathrm{H} \mathrm{H}_{2} \mathrm{O}$, compared with normal volume guarantee inflation. The interrupted expiration is most likely to be due to diaphragmatic braking.
\end{abstract}

$\mathrm{N}$ eonatal respiratory distress syndrome and bronchopulmonary dysplasia are associated with ventilator induced lung injury. ${ }^{12}$ Animal studies have shown lung over-distension and repeated re-inflation from atelectasis rather than high airway pressures per se causes lung damage. ${ }^{3}$ This has led to the practice of neonatal ventilation delivering relatively low tidal volumes $\left(\mathrm{V}_{\mathrm{T}}\right) .^{4}$ The $\mathrm{V}_{\mathrm{T}}$, delivered by the ventilator, is influenced by: compliance and resistance of the respiratory system, circuit gas flow, circuit compliance, endotracheal tube (ETT) resistance, inspiratory time, peak inspiratory pressure (PIP), and positive end expiratory pressure (PEEP). As most of these are reasonably constant, the PIP is the main determinant of each delivered $\mathrm{V}_{\mathrm{T}}$.

The Dräger Babylog 8000 ventilator (Dräger Medical, Lubeck, Germany) volume guarantee mode (VG) modulates the PIP to maintain the expired tidal volume $\left(\mathrm{V}_{\mathrm{Te}}\right)$ at a set value. The ventilator monitors inspiratory and expiratory flow at the ETT using a low dead space ( $1 \mathrm{ml}$ ) hotwire anemometer with a resolution of about $0.1 \mathrm{ml}$. The flow is integrated to calculate the inspired tidal volume $\left(\mathrm{V}_{\mathrm{Ti}}\right)$ and $\mathrm{V}_{\mathrm{Te}}$ for every inflation or spontaneous breath. $\mathrm{V}_{\mathrm{Te}}$ is used to modulate the PIP for the next inflation, because with a variable ETT leak $\mathrm{V}_{\mathrm{Te}}$ is closest to the $\mathrm{V}_{\mathrm{T}}$ that entered the lung. The PIP is altered for the next inflation to target the set $\mathrm{V}_{\mathrm{Te}}$ (see fig 1). Each change in PIP is limited to $3 \mathrm{~cm} \mathrm{H}_{2} \mathrm{O}$. There are separate programs controlling triggered and untriggered inflations. If the $\mathrm{V}_{\mathrm{Ti}}$ exceeds $130 \%$ of the set $\mathrm{V}_{\mathrm{Te}}$ inflation is stopped to prevent the ventilator contributing to a high tidal volume. High tidal volumes are usually due to the babies' large inspiratory efforts. The volume guarantee alters the PIP secondary to changes in lung compliance and the infant's breathing. This ensures mean tidal volumes close to the set tidal volume with reduced variability compared with ventilation using a set PIP. ${ }^{5}$
While monitoring flow, volume, and pressure waveforms, we noticed an unexpected expiratory pattern followed by increased inflating pressure during volume guarantee ventilation. The aim of this study was to describe the patterns of interaction between infant and ventilator during VG ventilation, and specifically investigate the unusual expiratory pattern we had observed.

\section{METHODS}

These studies were undertaken at the Royal Women's Hospital, Melbourne from September 2000 to May 2002. The Research and Ethics Committees agreed they could be done with verbal parental consent, as there was no interference with the baby or ventilator. A convenience sample of neonates were studied if the research team and equipment were available, the babies were breathing, weighed $>500 \mathrm{~g}$, were $<38$ weeks gestation, and were ventilated with the Dräger Babylog 8000 in VG, assist-control (SIPPV) mode. Infants were not studied if they had apnoea $>20$ seconds, a major congenital abnormality, periventricular leucomalacia, seizures, or an endotracheal tube leak $>60 \%$ of the $\mathrm{V}_{\mathrm{Ti}}$. Following the local protocol, VG, assist control ventilation was started on admission with a $\mathrm{V}_{\mathrm{Te}}$ of $5 \mathrm{ml} / \mathrm{kg}$, inspiratory time $0.3 \mathrm{~s}$, rate $\sim 60 / \mathrm{min}$, maximum PIP $30 \mathrm{~cm}$ $\mathrm{H}_{2} \mathrm{O}$, PEEP $\sim 5 \mathrm{~cm} \mathrm{H}_{2} \mathrm{O}$, flow $8 \mathrm{l} / \mathrm{min}$, and maximum trigger sensitivity. $\mathrm{PaCO}_{2}$ was maintained about $6-8 \mathrm{kPa}$ by adjusting the set $\mathrm{V}_{\mathrm{T}}$. At the time of these studies the set $\mathrm{V}_{\mathrm{T}}$ had changed from admission.

Flow and pressure waveforms were acquired from the ventilator analogue output and recorded at $200 \mathrm{~Hz}$ using the

Abbreviations: ETT, endotracheal tube; PEEP, positive end expiratory pressure; PIP, peak inspiratory pressure; $V G$, volume guarantee; $V_{T}$, tidal volume 


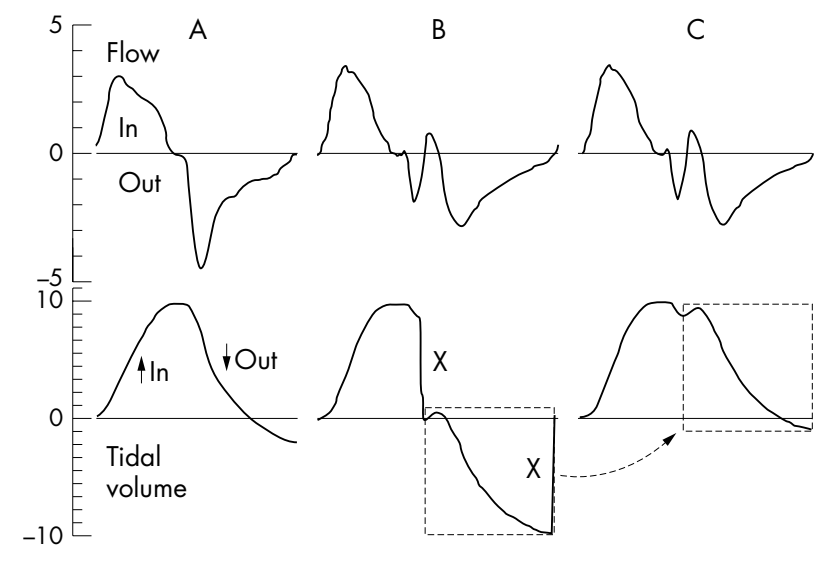

Figure 1 This illustrates the way the $V_{T}$ resets to zero when the flow crosses the zero line if the tidal volume is not at zero. The expired $V_{T}$ can then appear to become negative. This is because every time the flow crosses zero the tidal volume recording falsely resets to zero. This figure shows three parts. Part A shows a normal inspiratory and expiratory flow above and below the zero line with the tidal volume increasing and then decreasing. Part $B$ shows a normal inspiratory flow pattern with normal inspiratory $V_{T}$. The expiratory flow starts and then stops after only a small $V_{T e}$. A small inspiratory flow then occurs and as the flow crosses zero the $V_{T}$ rests to zero. The vertical line marked $X$ is not a true change in volume, it is just a resetting of the recording position. The remainder of the $\mathrm{V}_{T e}$ then appears to be negative. It is enclosed is a box with a dotted outline. Part $C$ shows exactly the same part of a recording as $B$, but here the $\mathrm{V}_{\mathrm{Te}}$ in the box has been moved and joined at the reset point to show that the $\mathrm{V}_{\mathrm{Te}}$ which appeared to be below the line was actually a normal expiratory volume curve.

Spectra physiological data acquisition program (Grove Medical Ltd, London, version 3.002). Flow waves are integrated to provide inspiratory and expiratory tidal volumes. With this program the tidal volume resets to zero every time the flow crosses the zero line and the volume is not at zero (see fig 1 for illustration and explanation). Simultaneously, data were recorded from: a pulse oximeter (Quartz Q-400, Quartz Medical Inc., Louisville, Colorado), and a transcutaneous $\mathrm{CO}_{2}$ and $\mathrm{O}_{2}$ monitor (TINA, Radiometer, Copenhagen, Denmark). Simultaneous video recording enabled the selection of artefact free epochs for analysis. The data were also analysed with a Labview 5.0 breath analysis program (National Instruments, Austin, Texas) created by one of the authors (PD). Breath identification was also checked manually.

The start of each recording coincided with a routine blood gas measurement to assess adequacy of ventilation and calibrate the transcutaneous monitor. Ventilator settings were unchanged during each study and the infant was not handled. Studies lasted about 30 minutes, and a 10 minute artefact free epoch was selected for analysis. The artefacts excluded were: crying, handling, hiccups, vigorous movement, or problems with the signal acquisition.

The VG mode controls the PIP independently for triggered and untriggered inflations (fig 1) so they were analysed separately. Calculating the time between inflations and comparing this with the set ventilator rate was used to identify whether they were triggered or untriggered. This was confirmed by examining the flow and pressure waveforms (fig 2; see legend). The time from the onset of inspiratory flow to the start of the inflating pressure was measured as the trigger delay. The $\mathrm{V}_{\mathrm{T}}$ delivered was analysed as a percentage of the set $\mathrm{V}_{\mathrm{Te}}$.

A significant difference was defined as $\mathrm{p}=0.05$ or less and statistical comparisons used a $t$ test for normal data and nonparametric tests for skewed data. Results are presented as mean (range) unless otherwise indicated. SPSS v 9.0 was used.

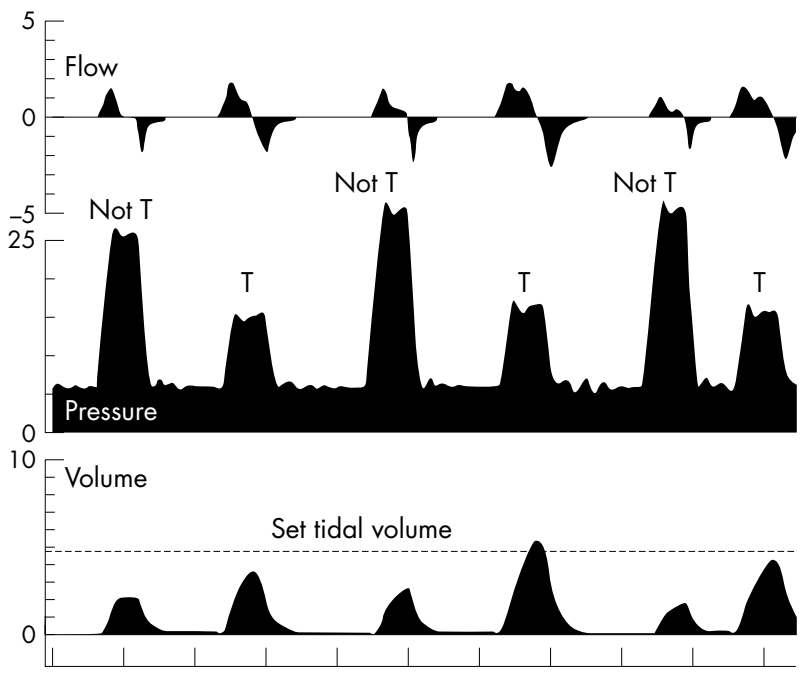

Figure 2 A recording of normal volume guarantee ventilation with the flow $(\mathrm{l} / \mathrm{min})$ at the top, ventilator pressure $\left(\mathrm{cm} \mathrm{H}_{2} \mathrm{O}\right)$ in the middle, and tidal volume $(\mathrm{ml})$ at the bottom. In all three the wave rising is an increase and falling is a decrease. The set $\mathrm{V}_{\mathrm{Te}}$ is shown as the dotted line. There are three triggered, waves 2,4 , and 6, marked $\mathrm{T}$, and three untriggered inflations, marked Not $T$, with the ventilator pressure varying for each type. As the inflating pressure is related to the preceding $V_{T e}$ and separate programs control untriggered and triggered inflations, the PIP for the triggered inflations 4 and 6 are related to how close the $V_{T e}$ was to the set $V_{T e}$ for the second and fourth inflation respectively. The PIP for the untriggered inflation 3 is increased compared with inflation 1 because the tidal volume for 1 was below the set tidal volume.

\section{RESULTS}

Ten infants were studied, with parental consent, and 6540 inflations examined in detail. The infants' characteristics are shown in table 1 . They all had satisfactory blood gas results. Adequate ventilation was maintained during each study: mean (SD) $\mathrm{SaO}_{2} 96 \%$ (3), transcutaneous carbon dioxide 6.2 (1.3) $\mathrm{kPa}$, and heart rate 142 (14) min.

Two patterns of VG ventilation were observed: normal VG, and interrupted expiration patterns.

\section{Normal VG pattern}

Normal VG ventilation was characterised by uninterrupted inspiratory and expiratory flow with small changes in PIP to maintain the set $\mathrm{V}_{\mathrm{Te}}$ (fig 3, first part; and fig 4). It was seen in $97 \%$ of triggered inflations and $91 \%$ of untriggered inflations. The mean and range of $\mathrm{V}_{\mathrm{Te}}$ for triggered and untriggered inflations are shown for individual infants in table 2 . The mean $\mathrm{V}_{\mathrm{Te}}$ was within $3 \%$ of the set $\mathrm{V}_{\mathrm{Te}}$ for both triggered and untriggered inflations, and there was no significant difference found between the delivered $\mathrm{V}_{\mathrm{Te}}$ and the set $\mathrm{V}_{\mathrm{Te}}$ for the combined triggered and untriggered inflations (mean difference $-0.02 \mathrm{ml}, 95 \% \mathrm{CI}-3.2$ to $2.8, \mathrm{p}=0.89$ ). There was wide variation in $\mathrm{V}_{\mathrm{T}}$ because sometimes the babies had large inspirations which produced tidal volumes higher than set (see last four inflations in fig 4); at other times the babies tensed their abdominal muscles and obstructed an inflation so the $\mathrm{V}_{\mathrm{Te}}$ was very low despite a high PIP (not illustrated).

\section{Interrupted expiration pattern}

The interrupted expiration pattern was characterised by expiratory flow interrupted by a small, short inspiration in the 0.2 second refractory period of the ventilator, followed by the rest of the expiration (fig 3, interrupted expiration; and fig 5). This occurred with $2.2 \%$ of triggered and $3.3 \%$ of untriggered inflations. Review of video recordings showed this was not due to hiccups, movement, handling, or crying. The number of inflations followed by an interrupted expiration varied for each 


\begin{tabular}{|c|c|c|c|c|c|}
\hline Infant & $\begin{array}{l}\text { Gestation } \\
\text { (weeks) }\end{array}$ & $\begin{array}{l}\text { Age at study } \\
\text { (days) }\end{array}$ & Weight at study (g) & Set $V_{\mathrm{Te}}(\mathrm{ml} / \mathrm{kg})$ & $\mathrm{FiO}_{2}$ \\
\hline 1 & 24 & 24 & 630 & 4.5 & 0.35 \\
\hline 2 & 24 & 24 & 800 & 3.7 & 0.31 \\
\hline 3 & 36 & 3 & 2780 & 2.9 & 0.28 \\
\hline 4 & 24 & 3 & 640 & 3.6 & 0.21 \\
\hline 5 & 32 & 3 & 1920 & 3.9 & 0.21 \\
\hline 6 & 37 & 1 & 3110 & 3.9 & 0.80 \\
\hline 7 & 26 & 1 & 739 & 4.6 & 0.21 \\
\hline 8 & 26 & 3 & 850 & 4.7 & 0.28 \\
\hline 9 & 30 & 2 & 1700 & 3.8 & 0.21 \\
\hline 10 & 34 & 1 & 2805 & 2.8 & 0.30 \\
\hline $\begin{array}{l}\text { Median } \\
\text { (range) }\end{array}$ & $28(24-37)$ & $3(1-24)$ & $1275(630-3110)$ & $3.85(2.8-4.7)$ & $0.28(0.21-0.8)$ \\
\hline
\end{tabular}

infant. During the 10 minutes analysed for each infant they ranged from 1 to 20 for triggered inflations, and from 1 to 38 for untriggered inflations.

The VG program interprets the small "interrupting" inspiration, early in expiration, as the end of expiration and the start of a new inflation. This leads it to calculate an incorrectly small $\mathrm{V}_{\mathrm{Te}}$. The mean volume for the first part of the $\mathrm{V}_{\mathrm{Te}}$, before the interruption, was 1.3 (range $0.1-4.3$ ) $\mathrm{ml} /$ $\mathrm{kg}$ (table 3). The mean $\mathrm{V}_{\mathrm{Te}}$ after the interruption was 4.1 (range 1.4l-14.1) $\mathrm{ml} / \mathrm{kg}$. A total $\mathrm{V}_{\mathrm{Te}}$ was calculated for each of these inflations by adding the initial $\mathrm{V}_{\mathrm{Te}}$ before the interruption, to the $\mathrm{V}_{\mathrm{Te}}$ after the interruption and subtracting the small inspiratory volume; the mean was 4.9 (range $0.2-$ 19.1 ) $\mathrm{ml} / \mathrm{kg}$ (table 3 ). The initial $\mathrm{V}_{\mathrm{Te}}$ averaged $35 \%$ of the set $\mathrm{V}_{\mathrm{Te}}$ and $37 \%$ of the actual delivered $\mathrm{V}_{\mathrm{Te}}$. Overall, the $\mathrm{V}_{\mathrm{Te}}$ was $125 \%$ of the set $\mathrm{V}_{\mathrm{Te}}$. The mean difference between set $\mathrm{V}_{\mathrm{Te}}$ and delivered $\mathrm{V}_{\mathrm{Te}}$ was $-0.97 \quad(95 \%$ CI -1.26 to -0.70$) \mathrm{ml}$ $(p<0.001)$. The small initial $\mathrm{V}_{\mathrm{Te}}$ led to an increase in PIP for the next inflation. This resulted in a $\mathrm{V}_{\mathrm{Ti}}$ for that inflation that often exceeded $130 \%$ of the set tidal volume (see above).

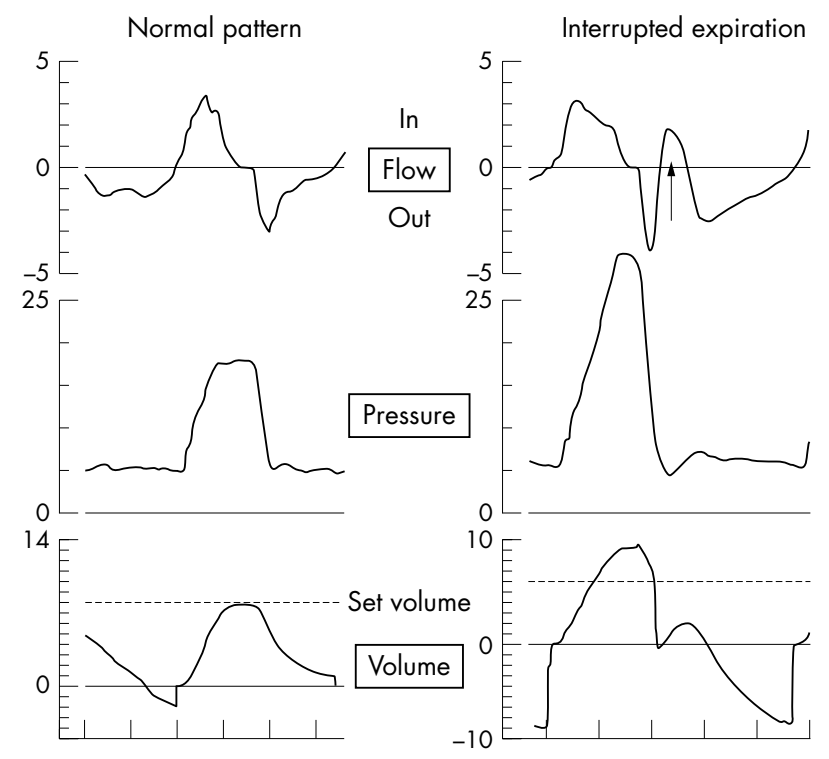

Figure 3 This illustrates the normal VG pattern and the interrupted expiration pattern. The three waves are flow $(\mathrm{l} / \mathrm{min})$, ventilator pressure $\left(\mathrm{cm} \mathrm{H} \mathrm{H}_{2} \mathrm{O}\right)$, and tidal volume $(\mathrm{ml})$ from top to bottom. The left hand graphs show the normal pattern seen during VG ventilation. The right hand graphs show interrupted expiration with the inspiration, indicated by the arrow, starting shortly after the end of inflation and separating the expiratory flow into two parts.
This caused the inflating pressure to be stopped by the VG program before the calculated PIP or inspiratory time were reached.

The PIP for normal VG inflations was 14.2 (SD 4.6) cm $\mathrm{H}_{2} \mathrm{O}$. This was less than 19.1 ( $\mathrm{SD} 6.1$ ) $\mathrm{cm} \mathrm{H}_{2} \mathrm{O}$ for inflations preceded by an interrupted expiration. The mean difference was -4.9 (95\% CI -5.6 to -4.2$) \mathrm{cm} \mathrm{H}_{2} \mathrm{O}(\mathrm{p}<0.001)$. Smaller pressure changes, positive or negative, were made between normal VG inflations (mean $0.8 \mathrm{~cm} \mathrm{H}_{2} \mathrm{O}$ ), compared with inflations preceded by an interrupted expiration (mean $2.8 \mathrm{~cm} \mathrm{H} \mathrm{H}_{2} \mathrm{O}$ ). The mean difference was -2.0 (95\% CI -2.2 to -1.7$)(\mathrm{p}<0.001)$.

Inflations followed by an interrupted expiration were more likely to increase the PIP for subsequent inflations (54\%) despite the larger total tidal volumes delivered, compared with normal VG inflations (43\%). For normal VG inflations the average pressure changes between inflations (positive or negative) was very small (mean -0.02 ( $\mathrm{SD} 1.7$ ) $\mathrm{cm} \mathrm{H}_{2} \mathrm{O}$ ), but for inflations after an interrupted expiration it was 0.38 (SD 4.4) $\mathrm{cm} \mathrm{H}_{2} \mathrm{O}(\mathrm{p}=0.005)$.
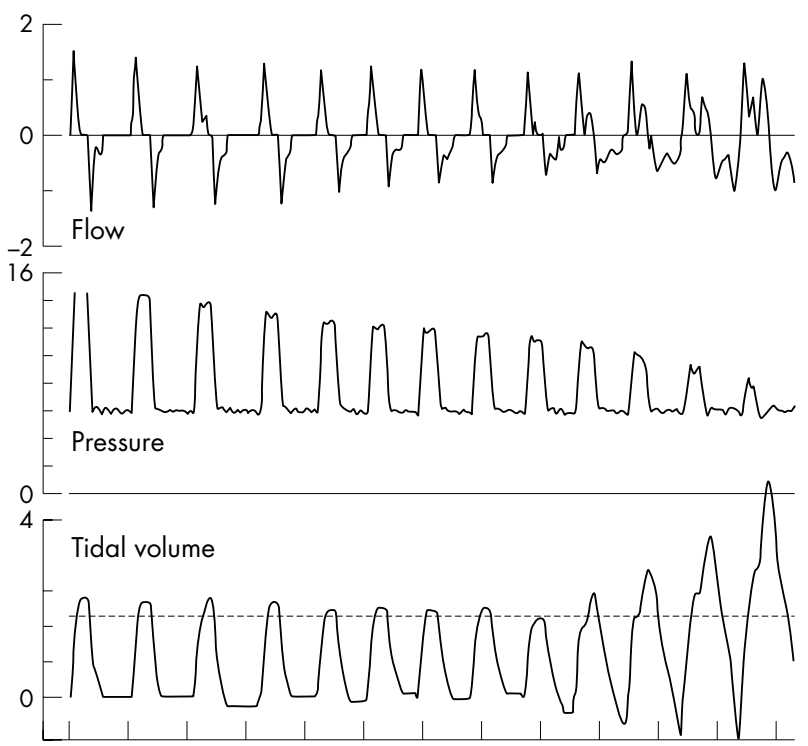

Figure 4 This shows normal assist control, VG ventilation with all inflations being triggered. The three waves are flow $(1 / \mathrm{min})$, ventilator pressure $\left(\mathrm{cm} \mathrm{H}_{2} \mathrm{O}\right)$, and tidal volume $(\mathrm{ml})$ from top to bottom. The PIP is reduced for each inflation where the previous $\mathrm{V}_{\mathrm{Te}}$ was greater than the set $\mathrm{V}_{\mathrm{T} \text { e }}$. However, during the last four inflations the baby inspires strongly during inflation, causing increasingly large tidal volumes despite low and reducing peak pressures. 
Table 2 Expired tidal volumes during volume guarantee ventilation with a normal expiratory pattern

\begin{tabular}{|c|c|c|c|}
\hline Infant & Set $V_{T e}(\mathrm{ml} / \mathrm{kg})$ & $\begin{array}{l}\mathrm{V}_{\mathrm{Te}} \text { during triggered inflations } \\
\text { Mean (range) }(\mathrm{ml} / \mathrm{kg})\end{array}$ & $\begin{array}{l}\mathrm{V}_{\mathrm{Te}} \text { during untriggered inflations } \\
\text { Mean (range) }(\mathrm{ml} / \mathrm{kg})\end{array}$ \\
\hline 1 & 4.5 & $4.5(0.06-16.8)$ & $4.3(0.01-14.3)$ \\
\hline 2 & 3.7 & $3.8(0.01-10.9)$ & $3.7(0.3-11.0)$ \\
\hline 3 & 2.9 & $2.7(1.5-43)$ & $2.7(2.0-4.3)$ \\
\hline 4 & 3.6 & $3.6(1.5-7.3)$ & $3.4(1.2-9.6)$ \\
\hline 5 & 3.9 & $3.7(0.6-8.8)$ & $3.8(1.8-8.3)$ \\
\hline 6 & 3.9 & $3.8(1.0-5.8)$ & $3.5(2.4-5.0)$ \\
\hline 7 & 4.6 & $4.6(0.01-11.8)$ & $4.5(0.02-11.3)$ \\
\hline 8 & 4.7 & $5.3(0.4-16.1)$ & $4.2(0.6-10.0)$ \\
\hline 9 & 3.8 & $3.9(1.3-5.7)$ & $5(0.5-6.1)$ \\
\hline 10 & 2.8 & $3.2(0.1-6.9)$ & $3.4(0.8-5.3)$ \\
\hline \multicolumn{4}{|c|}{ All infants combined, mean (range) as percentage of the set $V_{T e}$} \\
\hline & $100 \%$ & $102(0-378) \%$ & $98(0-322) \%$ \\
\hline
\end{tabular}

Results expressed as mean and range for triggered and untriggered inflations.

\section{DISCUSSION}

This study assessed the interaction between the Dräger Babylog 8000 ventilator and the quietly breathing infant receiving assist control, VG ventilation. Over $90 \%$ of inflations had a normal and expected pattern. Interrupted expiration occurred after about 3\% of inflations. In this the infant interrupts expiration with a small inspiration within the ventilator's refractory period, so that it does not trigger an inflation. The VG program misinterprets this as the end of expiration for that inflation and considers the first small $V_{T e}$ as the total $\mathrm{V}_{\mathrm{Te}}$. As this is less than the set $\mathrm{V}_{\mathrm{Te}}$ it increases the PIP for the next inflation to try and increase the next $\mathrm{V}_{\mathrm{Te}}$. A concern is that the increased PIP could deliver a large tidal volume. However, when the $\mathrm{V}_{\mathrm{Ti}}$ reached more than $130 \%$ of

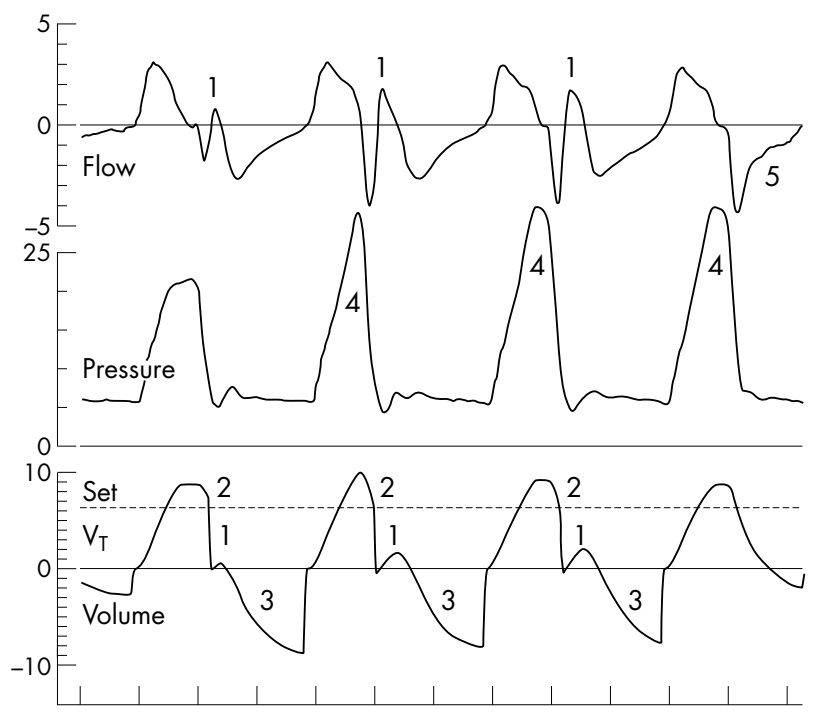

Figure 5 A recording showing the interrupted expiration pattern after four inflations. The flow $(1 / \mathrm{min})$, ventilator pressure $\left(\mathrm{cm} \mathrm{H}_{2} \mathrm{O}\right)$, and tidal volume $(\mathrm{ml})$ waves are in similar positions to the other figures, but the zero line for tidal volume is now in the middle of the tidal volume recording. After each of the first three inflations expiration is interrupted by a rapid small inspiration of variable volume, shown at each " 1 ". This results in small initial $V_{T e}$ shown at each " 2 ". This is the $V_{T e}$ that the ventilator reads to determine the PIP for the next inflation and is the reason why interrupted expiration causes the PIP to rise. The second part of the $V_{T e}$ is shown at each " $3^{\prime \prime}$. The increased PIP after the interrupted expirations are shown at " 4 ". The second inflating pressure is shorter than the first because the $\mathrm{V}_{\mathrm{Ti}}$ has reached $130 \%$ of the set $\mathrm{V}_{\mathrm{Te}}$ and so the inflation was stopped before the end of the inflation time. The last inflation shows a normal expiratory flow curve at " 5 ". the set $\mathrm{V}_{\mathrm{Te}}$ the ventilator stopped the inflation. On the few occasions when larger tidal volumes occurred this was due to the baby's inspiration. Even when large tidal volumes were delivered they were not perpetuated in subsequent triggered or untriggered normal inflations.

We think the interrupted expiration is due to diaphragmatic contraction, probably as part of expiratory braking. ${ }^{6-8}$ In many expiratory flow curves, after normal inflations, there was a notch where the flow was temporarily slowed (fig 6). Occasionally it was briefly stopped and then resumed. This could not be due to increased expiratory resistance or airway obstruction and can only be caused by inspiration. This could not be due to laryngeal braking because the endotracheal tube bypassed the larynx. In fig 6 it can be seen that with the small inspirations the PEEP pressure fell slightly, supporting the idea that these are spontaneous inspirations. We have not seen this pattern in ventilated, muscle relaxed infants or anaesthetised premature lambs. ${ }^{9}$ If this is part of an expiratory braking mechanism it may indicate the infant has a low lung volume. We investigated whether increasing PEEP changed the pattern but, in limited observations, it had no obvious effect. It has been known that premature infants

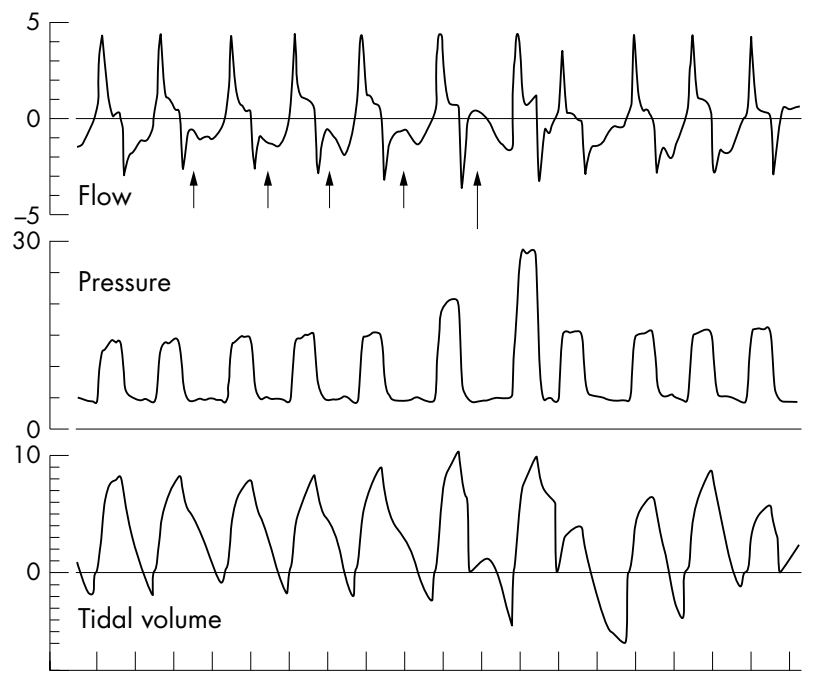

Figure 6 This illustrates the changing expiratory flow pattern after a series of inflations. The first expiratory flow is a normal pattern. In the next four expiratory flow waves the flow wave is concave (arrows), showing a transient slowing of expiration. The fifth expiratory flow has an interrupted expiration (large arrow). The subsequent expiratory flow waves have a slightly concave waves. 


\begin{tabular}{|c|c|c|c|c|}
\hline \multirow[b]{2}{*}{ Infant } & \multirow[b]{2}{*}{$\begin{array}{l}\text { Set } V_{\text {Te }} \\
(\mathrm{ml} / \mathrm{kg})\end{array}$} & \multicolumn{3}{|c|}{$\begin{array}{l}\text { Mean and (range) of } V_{T e}(\mathrm{ml} / \mathrm{kg} \text { ) for inflations followed by } \\
\text { an interrupted expiration }\end{array}$} \\
\hline & & $\begin{array}{l}\text { 1st part before } \\
\text { interruption }\end{array}$ & $\begin{array}{l}\text { 2nd part after } \\
\text { interruption }\end{array}$ & $\begin{array}{l}\text { Delivered } \mathrm{V}_{\mathrm{Te}} \\
\text { overall }\end{array}$ \\
\hline 1 & 4.5 & $1.3(0.2-3.9)$ & $5.6(3.6-7.95)$ & $5.6(3.6-7.95)$ \\
\hline 2 & 3.7 & $1.9(0.5-4.3)$ & $3.7(1.4-14.1)$ & $4.9(0.2-19.1)$ \\
\hline 3 & 2.9 & $0.9(0.2-1.7)$ & $3.1(1.9-5.8)$ & $3.6(2.5-5.8)$ \\
\hline 4 & 3.6 & $1.5(0.7-2.7)$ & $6.0(2.6-11.5)$ & $4.3(4-4.7)$ \\
\hline 5 & 3.9 & $2.1(1.2-2.8)$ & $3.0(1.7-4.9)$ & $4.4(1.0-9.3)$ \\
\hline 6 & 3.9 & $0.7(0.3-1.7)$ & $3.6(1.9-5.7)$ & $3.9(2.3-5.7)$ \\
\hline 7 & 4.6 & $1.1(0.01-1.8)$ & $4.3(2.1-9.2)$ & $5.5(2-10.4)$ \\
\hline 8 & 4.7 & $1.3(0.1-3.5)$ & $5.6(2.0-10.5)$ & $5.9(2.6-10.5)$ \\
\hline 9 & 3.8 & $1.2(0.1-2.7)$ & $3.9(1.9-5.2)$ & $5.2(2.8-6.2)$ \\
\hline 10 & 2.8 & $0.4(0.3-1.7)$ & $3.6(1.9-5.7)$ & $3.7(3.7-3.8)$ \\
\hline All inflations, mean (SD) & $3.9(0.53)^{*}$ & $1.3(0.9)$ & $4.1(2.0)$ & $4.9(2.0)$ \\
\hline $\begin{array}{l}\text { Mean }(S D) \text { as \% of the } \\
\text { set } V_{T e}\end{array}$ & $100 \%$ & $35(22) \%$ & $104(47) \%$ & $125(49) \%$ \\
\hline $\begin{array}{l}\text { Difference from the } \\
\text { delivered } \mathrm{V}_{\mathrm{Te}}(\mathrm{ml} / \mathrm{kg}) \text {, } \\
\text { mean }(95 \% \mathrm{Cl})\end{array}$ & $\begin{array}{l}-1.0 \\
(-1.3 \text { to }-0.7)^{*}\end{array}$ & $3.5(3.2 \text { to } 3.8)^{*}$ & $0.8(0.5-1.1)^{*}$ & \\
\hline \multicolumn{5}{|c|}{$\begin{array}{l}\text { Shows the mean and ranges of the expired volumes during the first part, before the interruption, the part after the } \\
\text { interruption, and the total. The last line shows the mean and SD for all infants and the difference between the total } \\
\text { expired volume and the set expired tidal volume. } \\
{ }^{*} \mathrm{p}<0.001 \text {. }\end{array}$} \\
\hline
\end{tabular}

maintain an increased end expiratory lung volume produced in part by post-inspiratory diaphragmatic activity which is increased by hypercarbia. ${ }^{6}$ However, the infants in this study were not hypercarbic. It is possible this pattern is more common in ventilated premature infants than has been realised. We have noticed it in other ventilation modes. However, it is not so obvious there because without the VG mode the ventilator does not respond by changing the PIP after an interrupted expiration.

Inflations followed by interrupted expiration were more likely to be followed by an increase in PIP for the next inflation than after normal inflations. This was often restricted by (a) the VG program limiting the PIP if the $\mathrm{V}_{\mathrm{Ti}}$ was more than $130 \%$ of that set, or (b) to no more than a $3 \mathrm{~cm} \mathrm{H}_{2} \mathrm{O}$ increase between inflations. This lessened the impact of interrupted expiration on subsequent tidal volumes. This phenomenon did not result in dangerously large tidal volume, because of the safety factor built into the software.
To ensure the interrupted expiratory pattern was not due to artefacts we tried to imitate the pattern in the laboratory by using water oscillating in the expiratory limb of the ventilator circuit. We also set the ventilator circuit bouncing and vibrating. Both techniques failed to produce the pattern of interrupted expiration.

The VG mode controlled the mean $\mathrm{V}_{\mathrm{Te}}$ within 3\% of the set $\mathrm{V}_{\mathrm{Te}}$ for triggered and untriggered inflations. There was a large variation in $\mathrm{V}_{\mathrm{Te}}$. This was due to: (a) infants suddenly taking a deep breath that exceeded the set $\mathrm{V}_{\mathrm{Te}}$ (see end of fig 4); (b) infants occasionally opposing inflation by tightening their abdominal muscles ${ }^{10}$ (this reduced and occasionally stopped some inflations); or (c) with interrupted expiration, the first part of the $\mathrm{V}_{\mathrm{Te}}$ was considerably less than the set $\mathrm{V}_{\mathrm{Te}}$.

The high proportion of untriggered inflations was due to the ventilator rate being set at $60 / \mathrm{min}$ and therefore close to the babies' spontaneous rate. The purpose of assist control ventilation is to augment each of the infant's spontaneous inspirations with an inflation. If the ventilator rate is too

\begin{tabular}{|c|c|c|c|c|c|}
\hline \multirow[b]{2}{*}{ Infant } & \multirow[b]{2}{*}{$\begin{array}{l}\text { Set } V_{T e} \\
(\mathrm{ml} / \mathrm{kg})\end{array}$} & \multicolumn{2}{|c|}{$\begin{array}{l}\mathrm{V}_{\mathrm{Te}}(\mathrm{ml} / \mathrm{kg} \text { ) for triggered inflations } \\
\text { Mean (range) }\end{array}$} & \multicolumn{2}{|c|}{$\begin{array}{l}\mathrm{V}_{\mathrm{T}} \text { (ml/kg) for untriggered inflations } \\
\text { Mean (range) }\end{array}$} \\
\hline & & $\begin{array}{l}\text { Interrupted } \\
\text { expiration }\end{array}$ & Next inflation & $\begin{array}{l}\text { Interrupted } \\
\text { expiration }\end{array}$ & Next inflation \\
\hline 1 & 4.5 & 7.3 & 4.4 & $5.2(3.6-8.0)$ & $4.3(3.4-5.0)$ \\
\hline 2 & 3.7 & $5.8(2.1-19.1)$ & $4.6(2.1-10.9)$ & $3.1(0.2-3.9)$ & $3.8(2.9-4.7)$ \\
\hline 3 & 2.9 & $3.7(3.0-5.8)$ & $3.5(2.7-4.3)$ & $3.5(2.5-4.4)$ & $3.5(2.1-4.3)$ \\
\hline 4 & 3.6 & $4.3(4.0-4.7)$ & $4.3(3.9-4.7)$ & $4.3^{\circ}$ & 3.4 \\
\hline 5 & 3.9 & $4.6(1.0-9.3)$ & $4.5(1.3-7.5)$ & $4.1(2.8-5.9)$ & $5.2(3.0-6.3)$ \\
\hline 6 & 3.9 & $4.0(2.3-5.7)$ & $3.9(2.8-5.7)$ & $3.8(2.8-5.4)$ & $3.2(2.5-4.1)$ \\
\hline 7 & 4.6 & 4.0 & 5.0 & $6.0(2.1-10.4)$ & $5.1(4.7-6.1)$ \\
\hline 8 & 4.7 & $6.5(0.1-10.5)$ & $4.7(1.1-8.2)$ & $4.8(2.6-8.0)$ & $5.3(2.0 .3)$ \\
\hline 9 & 3.8 & $4.3(3.5-5.6)$ & $3.9(3.0-4.4)$ & $5.4(2.8-6.2)$ & $5.2(0.6-6.3)$ \\
\hline 10 & 2.8 & 3.8 & 3.0 & & \\
\hline $\begin{array}{l}\text { Percentage } \\
\text { of set } \mathrm{V}_{\mathrm{Te}}\end{array}$ & $100 \%$ & $127 \%(0-512)$ & $103 \%(0-512)$ & $123 \%(5-227)$ & $101 \%(0-322)$ \\
\hline
\end{tabular}

The number of inflations followed by interrupted expiration varied for each infant. Where no range is given there was only one value available. 


\section{What is already known on this topic}

- Volume guarantee ventilation controls the mean expired tidal volume accurately but with considerable variation

- The variability of PIP during volume guarantee ventilation

- Diaphragmatic, expiratory braking has been described

close to the spontaneous rate this does not happen, and an untriggered inflation is delivered out of synchrony with any spontaneous efforts. The high rate of untriggered inflations is not due to insensitivity of the trigger. In retrospect, the ventilator rate was probably set a little too high for effective assist control triggering.

Other studies have investigated VG ventilation but none have reported the pattern of interrupted expiration and the consequent small tidal volumes followed by a high PIP. ${ }^{5} 11$ Cheema and Ahluwalia ${ }^{11}$ set the maximum PIP to that used during pressure limited ventilation, and so this restricted the ability of the VG to compensate for low delivered volumes by increasing PIP above this level. They recorded the data every 10 seconds, then averaged to every minute. This will have blunted their assessment of the variability in PIP and tidal volume. Abubakar and Keszler ${ }^{12}$ found the mean PIP was more variable when VG was used. Tidal volume variability was reduced, but not eliminated by VG. However, they excluded breaths that suffered distortion, artefact, hiccups, or movement. This may have inadvertently altered the analysis. Herrera and colleagues ${ }^{5}$ compared synchronised intermittent mandatory ventilation (SIMV) alone with SIMV and VG at different set tidal volumes during 45 minute studies. They found that SIMV + VG was associated with a significant reduction in mechanical support compared with SIMV alone and no adverse effects were seen. They did not comment on any interactions of the infant and ventilator and whether this affected their results.

While ventilator triggering and tidal volume targeting aim to improve the way infant and ventilator work together efficiently to minimise lung injury, this study has shown that the interactions between the infant and ventilator are complex and still need to be carefully considered to optimise synchronous ventilation.

The limitations of this study are that only 10 infants were studied and there were only $\sim 600$ inflations for each infant. It is possible that the incidence of interrupted expirations and their associated phenomena would be different in other groups of infants. Although our hypothesis is that this pattern represented expiratory braking, we were not able to prove this by measuring diaphragmatic EMG or lung volume.

\section{Conclusion}

This study analysed in detail the interaction between the Dräger Babylog 8000 ventilator in volume guarantee assist control mode and the spontaneously breathing intubated infant. It has shown that in the majority of inflations the PIP varied to target the expired tidal volume as programmed. The mean $V_{\mathrm{Te}}$ for these inflations was within 3\% of the set value,
What this study adds

- A very detailed assessment of the way volume guarantee works inflation by inflation

- An assessment of the effect of triggered and nontriggered inflations

- A description of the phenomenon of interrupted expiration during neonatal ventilation

- Information about diaphragmatic expiratory braking during neonatal ventilation

although there was a wide variation due to the breathing patterns of the baby. It also identified a small proportion of inflations with an "interrupted expiration" pattern where a small inflation interrupted expiration and that interfered with calculation of the $\mathrm{V}_{\mathrm{Te}}$ and inappropriately increased the PIP for the next inflation. We postulate this was due to diaphragmatic expiratory braking.

\section{ACKNOWLEDGEMENTS}

Peter Dargaville and Naomi McCallion were holders of a Murdoch Children's Research Institute, Senior Research Fellow and a Royal Women's Research Fellowship, respectively.

\section{Authors' affiliations}

N McCallion, R Lau, C J Morley, Dept of Neonatal Medicine, Royal

Women's Hospital, Melbourne, Victoria, Australia

P A Dargaville, Dept of Neonatology, Royal Children's Hospital,

Melbourne, Victoria, Australia

Competing interests: none declared

\section{REFERENCES}

1 Jobe AH, Ikegami M. Prevention of bronchopulmonary dysplasia. Curr Opin Pediatr 2001;13:124-9.

2 Coalson JJ, Winter VT, Siler-Khodr T, et al. Neonatal chronic lung disease in extremely immature baboons. Am J Respir Crit Care Med $1999 ; 160: 1333-46$

3 Hernandez LA, Peevy KJ, Moise AA, et al. Chest wall restriction limits high airway pressure-induced lung injury in young rabbits. J Appl Physiol 1989:66:2364-8

4 Clark RH, Slutsky AS, Gerstmann DR. Lung protective strategies of ventilation in the neonate: what are they? Pediatrics 2000;105:112-14.

5 Herrera CM, Gerhardt T, Claure N, et al. Effects of volume-guaranteed synchronized intermittent mandatory ventilation in preterm infants recovering from respiratory failure. Pediatrics 2002;1 10:529-33.

6 Eichenwald EC, Ungarelli RA, Stark AR. Hypercapnia increases expiratory braking in preterm infants. J Appl Physiol 1993;75:2665-70.

7 Kosch PC, Hutchinson AA, Wozniak JA, et al. Posterior cricoarytenoid and diaphragm activities during tidal breathing in neonates. J Appl Physiol 1988;64:1968-78

8 Hutchison AA, Wozniak JA, Choi HG, et al. Laryngeal and diaphragmatic muscle activities and airflow patterns after birth in premature lambs. J Appl Physiol 1993;75:121-31.

9 Probyn M, Hooper SB, Dargaville PA, et al. Positive end expiratory pressure (PEEP) during resuscitation of premature lambs rapidly improves blood gases without adversely affecting arterial pressure. Pediatr Res. In press.

10 Bolivar JM, Gerhardt T, Gonzalez A, et al. Mechanisms for episodes of hypoxemia in preterm infants undergoing mechanical ventilation. J Pediatr 1995; 127:767-73.

11 Cheema IU, Ahluwalia JS. Feasibility of tidal volume-guided ventilation in newborn infants: a randomised, crossover trial using the volume guarantee modality. Pediatrics 2001;107:1323-8.

12 Abubakar KM, Keszler M. Patient-ventilator interactions in new modes of patient-triggered ventilation. Pediatr Pulmonol 2001;32:71-5. 